\title{
Objectively-Measured Neighbourhood Attributes as Correlates and Moderators of Quality of Life in Older Adults with Different Living Arrangements: The ALECS Cross-Sectional Study
}

\author{
Casper J. P. Zhang ${ }^{1}\left(\mathbb{D}\right.$, Anthony Barnett ${ }^{2}$, Janice M. Johnston ${ }^{1}{ }^{\mathbb{D}}$, Poh-chin Lai $^{3}{ }^{\mathbb{C}}$, \\ Ruby S. Y. Lee ${ }^{4}$, Cindy H. P. Sit ${ }^{5}$ and Ester Cerin ${ }^{1,2, *(1)}$ \\ 1 School of Public Health, The University of Hong Kong, Hong Kong, China; \\ casperz1@connect.hku.hk (C.J.P.Z.); jjohnsto@hku.hk (J.M.J.) \\ 2 Mary MacKillop Institute for Health Research, Australian Catholic University, Melbourne, Victoria 3000, \\ Australia; Anthony.Barnett@acu.edu.au \\ 3 Department of Geography, Faculty of Social Sciences, The University of Hong Kong, Hong Kong, China; \\ pclai@hku.hk \\ 4 Elderly Health Service, Department of Health, The Government of Hong Kong Special Administration \\ Region, Hong Kong, China; ruby_sy_lee@dh.gov.hk \\ 5 Department of Sports Science and Physical Education, Faculty of Education, \\ The Chinese University of Hong Kong, Hong Kong, China; sithp@cuhk.edu.hk \\ * Correspondence: ecerin@hku.hk; Tel.: +61-392-308-260
}

Received: 7 February 2019; Accepted: 7 March 2019; Published: 10 March 2019

\begin{abstract}
With an ageing world population, preservation of older adults' health and quality of life (QoL) is paramount. Due to lower levels of physical functionality, older adults are particularly susceptible to local environment influences, especially those living alone and lacking family support. Using generalised additive mixed models, we examined associations and confounder-adjusted associations between objectively-measured neighbourhood attributes and QoL domains in 909 Hong Kong Chinese elderly community dwellers. Most examined neighbourhood attributes were not associated with QoL in the whole sample. Neighbourhood residential and entertainment density was curvilinearly and/or linearly related to specific QoL domains. Number of parks was negatively associated with social QoL and having well-treed parks with higher levels of social QoL. Older adults living alone in neighbourhoods with poor access to destinations and few activities in parks showed lower environmental and/or social QoL than their counterparts. Neighbourhood built environment characteristics do not seem to impact Hong Kong older adults' physical and psychological QoL. Medium-to-high density, well-ordered neighbourhoods with optimal mixes of well-treed public open spaces and services meeting their daily needs may significantly contribute to social and environmental QoL in this population and appear particularly important to those living alone.
\end{abstract}

Keywords: geographic information systems; environmental audits; living arrangements; mega-city; walkability; Hong Kong; social support; mental health

\section{Introduction}

According to the World Health Organisation (WHO), quality of life (QoL) refers to people's perceptions of their status in life in relation to their goals, standards and concerns, and within the context of their culture and value systems. This concept spans a wide range of aspects of life, including and beyond mere physical and mental health defined as the presence and severity of diseases [1]. The breadth of the WHO's definition of QoL is reflected in its domain-based QoL scales, the WHOQOL-100 
and WHOQOL-BREF, that capture a person's physical health, psychological state, social relations and satisfaction with essential features of the proximal and distal environment [1].

With extended life expectancy, an increasing proportion of the world population is likely to experience poorer QoL due to age-related chronic health problems and declines in physical functioning and mobility [2]. It is, thus, important to identify large-scale modifiable factors that can help older adults preserve good health and QoL. Among various factors, the physical characteristics of the neighbourhood environment in which older adults live are deemed to influence all domains of QoL [3]. Older adults' lower levels of physical functionality and mobility make them particularly susceptive to the influence of their local environment. For instance, a well-maintained pedestrian infrastructure can facilitate older people's engagement in recreational and utilitarian walking, which, in turn, may benefit their physical health and help them maintain their independence [4]. Access to diverse destinations in the neighbourhood may provide opportunities for social interaction, which is essential for psychological QoL [5,6]. These environmental features can also contribute to older adults' satisfaction with their neighbourhood environment [7]. On the other hand, adverse neighbourhood attributes, such as noise and physical barriers to walking, may have negative effects on QoL [8].

Several studies have found associations between physical attributes of the neighbourhood environment and QoL in older adults. For example, various aspects of neighbourhood safety and quality were positively associated with health-related QoL $[9,10]$. Higher levels of perceived access to services, shops and public transport were predictive of higher physical and social QoL [9]. Older adults living in neighbourhoods with safe and aesthetically-pleasing parks reported higher levels of physical and psychological QoL $[3,11]$, and spending more time in green areas was found to benefit mental well-being [12].

Most of the studies examining physical environmental correlates of QoL used self-report measures of environmental attributes [3]. Among the handful of studies that used objective measures of the environment [3,13-17], half of them employed a single composite index or variable [14-16], while the others examined two to four characteristics. The fact that most studies in this field relied on self-report measures of the environment is problematic because these, in this particular context, are associated with a higher risk of reverse causality than their objective counterparts. Specifically, older adults with better physical and psychological QoL may perceive their neighbourhood environment more positively than their counterparts because their affective states are more positive [18-20] and/or they are more mobile and capable of negotiating environmental barriers [21]. Additionally, affective states have been shown to influence perceptions of distance to destinations and slope steepness, whereby, for example, sadder and more fatigued people perceived hills to be steeper and destination distances to be greater than happier and less fatigue people [22]. These findings suggest that people's QoL and accompanying affective states can influence their perceptions of the neighbourhood environment gauged by self-report measures. Therefore, the use of objective measures to quantify environmental attributes, such as geographic information systems (GIS) [23] or environmental audits conducted by independent assessors [24], can plausibly provide more robust evidence of potential causal effects of the neighbourhood environment on QoL than self-report measures, although, understandably, they cannot not address neighbourhood self-selection bias within the context of observational studies.

Social-ecological models posit that health and well-being outcomes are shaped by the interaction of multiple levels of influences, including environmental, social and individual factors [25]. In the context of these theoretical models, attributes of the neighbourhood environment may directly impact on QoL and/or moderate the effects of other factors on QoL [25]. Among the many key contributors to QoL in later life that may be moderated by attributes of the neighbourhood environment are living arrangements, which represent a micro-environmental (household composition) as well as a social (proxy for access to social contacts and support) factor. There is substantial evidence that, compared to those living with others, older adults living alone tend to receive less personal assistance and emotional support, which results in more negative psychological states [20] and QoL perceptions [26]. In studies conducted in Hong Kong, older adults living alone reported poorer QoL and self-rated health 
status, limited social networks of relatives, lack of emotional and instrumental support [27] and more depressive symptoms $[20,27]$. Given the increasing prevalence of older urban dwellers living alone in Western [28] as well as Asian cities, such as Hong Kong [29], it is important to identify modifiable factors that can mitigate the negative effects of living arrangements on older adults' well-being. It is plausible to assume that living in a neighbourhood that provides good access to health-related services and opportunities for engagement in various social and health-enhancing activities may buffer the negative effect of living alone on QoL [30]. To our knowledge, no studies have examined the moderating effects of the neighbourhood environment on the association between living arrangements and QoL.

Our study aimed to examine the associations between objectively-measured neighbourhood physical environmental attributes and QoL domains in Hong Kong older community dwellers and estimate the moderating effects of neighbourhood environmental attributes on the associations of living arrangements with QoL. We hypothesised that: (1) objective measures of availability of/access to destinations, public open spaces/parks and pedestrian-friendly infrastructure would be positively associated with QoL domains; (2) adverse environmental attributes, such as pollution and traffic-related hazards, would be negatively associated with QoL domains; (3) better access to/availability of destinations and lower levels of adverse environmental attributes would mitigate the negative effect of living alone on QoL.

\section{Materials and Methods}

\subsection{Study Design and Neighbourhood Selection}

This study used data from the Active Lifestyle and the Environment in Chinese Seniors (ALECS) project, an observational investigation of associations between neighbourhood environment, physical activity, depressive symptoms and QoL in Hong Kong Chinese elderly community dwellers. The ALECS project used a two-stage sampling method to recruit participants from 124 tertiary planning units (TPUs) stratified by high/low socio-economic status (SES) and walkability to maximise the variation in environmental characteristics. TPUs are the smallest administrative area units with census data in Hong Kong. TPU-level SES was defined using Census data on median household income. TPUs were classified into high and low walkable based on a walkability index consisting of the sum of TPU-level z-scores for net residential density, intersection density and land-use mix derived using GIS data. Details about study design and neighbourhood selection have been reported elsewhere [31]. Ethics approval for the conduct of this study was obtained by the Department of Health of Hong Kong SAR and The University of Hong Kong Human Research Ethics Committee for Non-Clinical Faculties (ethics approval no.: EA270211; 22 February 2011).

\subsection{Participants}

Participants were recruited from the Elderly Health Centres (EHCs) and elderly community centres located in the pre-selected TPUs. The EHCs were established by the Department of Health of the Hong Kong Special Administrative Region to provide healthcare services to persons aged 65+ years and are distributed across all 18 Hong Kong districts. Although EHC clients are representative of the general Hong Kong elderly population in terms of age and SES, they tend to be more health-conscious than their counterparts [32]. To examine potential bias (better health-related QoL) associated with being a client of the EHCs, approximately $30 \%$ participants were recruited from elderly community centres with no formal provision of medical and health services. No significant differences between participants from the two types of recruitment centres were observed in age, physical health, marital status, living arrangements, type of neighbourhood of residence, type of housing, car in the household and health-related QoL (i.e., physical and psychological QoL). Participants from the EHCs tended to be more educated $(p=0.018)$, more likely to be men $(p=0.010)$ and reporting lower environmental QoL $(p=0.002)$ than their counterparts. 
Due to restricted access to residential addresses and other contact details mandated by the Hong Kong Personal Data (Privacy) Ordinance [33], potential participants were approached in person and recruited upon the verification of their eligibility and provision of signed informed consent. Eligibility criteria were being a Cantonese speaker, 65+ years of age, cognitively-intact, able to walk without assistance for $\geq 10 \mathrm{~m}$, and having lived in one of the pre-selected TPUs for at least six months. This study included 909 participants, with a response rate of $71 \%$ (1602 contacted; 322 ineligibles; 471 did not consent). Details of recruitment procedures have been described elsewhere [31].

\subsection{Measures}

\subsubsection{Exposures: Neighbourhood Attributes}

Extant GIS data and newly-collected data from environmental audits were used to objectively assess neighbourhood environmental attributes. Extant GIS data were sourced from the Census and Statistics, Lands, and Planning Departments of the Hong Kong Special Administrative Region. To quantify relevant neighbourhood attributes using extant GIS data, participant residential buffers, representing individual neighbourhood boundaries, were created by geocoding the residential addresses of each participant and then tracing from the participants' residences through the unique street networks in all directions for 400 and $800 \mathrm{~m}$, which are considered to be walkable distances and appropriate geographical scales for older adults living in high density environments [3,23]. GIS-based environmental attributes were computed for each participant and each buffer size (i.e., $400 \mathrm{~m}$ and $800 \mathrm{~m}$ radii) using Esri's ArcGIS software (Table S1). Given that there is no consensus about the optimal residential buffer size for studying relationships between neighbourhood attributes and older adults' health-related outcomes $[4,34]$, no hypotheses were formulated with regards to the buffer size that would yield stronger associations.

Environmental audits were employed to quantify neighbourhood attributes that were not assessable via extant GIS data (e.g., signs of crime/disorder) or for which the archival GIS database was outdated or incomplete. Crow-fly buffers of $400 \mathrm{~m}$ centred at participant residences were used as areas for environmental audits. We used $400 \mathrm{~m}$ crow-fly buffers rather than $400 \mathrm{~m}$ and $800 \mathrm{~m}$ street-network buffers for environmental audits for two reasons. First, study resources were insufficient to conduct environmental audits of all $400 \mathrm{~m}$ and $800 \mathrm{~m}$ street-network buffers (909 participants $* 2$ buffers $=$ 1018 buffers in total) used for the computation of neighbourhood attributes based on extant GIS data. Second, previous audits conducted in Hong Kong indicated that a $400 \mathrm{~m}$ crow-fly distance corresponded to a street network distance from 400 to $~ 900 \mathrm{~m}[24,35]$, implying that the sizes of $400 \mathrm{~m}$ crow-fly residential buffers would fall between those of $400 \mathrm{~m}$ and $800 \mathrm{~m}$ street-network buffers used in this study. Environmental audits were undertaken by trained auditors using the Environment in Asian Scan Tool-Hong Kong (EAST-HK) [24] and the Public Open Space Tool (POST) [36]. To identify street segments for auditing within the $400 \mathrm{~m}$ crow-fly residential buffers, all segments of major roads/streets that were accessible to pedestrians were selected. If the number of selected street segments in a specific buffer was less than a quarter of the total number of segments included in that buffer, additional segments (from minor roads) were randomly selected. A validation study of the EAST-HK suggested that $25 \%$ street segments were sufficient to obtain representative estimates of various environmental attributes in Hong Kong neighbourhoods [24]. Prior to data collection, novice auditors were trained until $95 \%$ agreement between their ratings and those of experienced auditors was reached. If during data collection auditors were unsure how to rate a specific audit item, they consulted other experienced auditors in real time (i.e., shared street-segment photos and questions/comments via mobile phone) and recorded a consensual rating.

Single and multiple EAST-HK items assessed the presence of particular environmental attributes (Table S1) in each street segment defined as a section of a street between intersections. Environmental attributes were measured and aggregated by participant buffer. Scores on single-item measures denoted the percentage of audited street segments within a buffer with a particular attribute, while 
scores on multiple-item measures referred to the percentage of the highest obtainable score (determined by the number of items) averaged across audited street segments within a buffer. The POST assessed several features of all public parks that intersected a participant's buffer (Table S1). These included the presence and/or location of trees, paths and amenities, and park aesthetics and visibility from surrounding areas. The maximum scores of these characteristics across all intersected parks were obtained for each participant buffer, while the total number of activity types was tallied across all parks intersecting a buffer.

\subsubsection{Outcome: Quality of Life}

QoL was measured via interviewer-administration of the WHOQOL-BREF, the abbreviated QoL questionnaire developed by the WHO. The Hong Kong Chinese version of the WHOQOL-BREF [37] contains 26 items (24 core items and two additional items specific to Hong Kong) measuring four QoL domains: physical health (seven items), psychological health (eight items, including two Hong Kong specific items), social relationships (three items) and environment (eight items). Each item was rated on a 5-point scale. Item scores for each domain were computed and converted to standardised scores ranging from 4 to 20 according to pre-established procedures [38].

\subsubsection{Covariates}

Covariates included in all analyses were age (years), gender (female vs. male), educational attainment (no formal education, primary school, secondary school and post-secondary school), marital status (married or cohabiting, widowed, and other), living arrangement (living with others vs. living alone), housing type (public and aided, private and renting), availability of car in the household (yes vs. no), area-level SES (high vs. low), type of recruitment centres (EHC vs. elderly community centre) and the number of diagnosed health problems. The latter was obtained using information from a clinical health-problems checklist obtained from the EHC (based on medical staff assessments) or, for those recruited at elderly community centres, from the participants at the interview.

\subsubsection{Analytical Approaches}

Descriptive statistics were computed for all variables. Generalised additive mixed models (GAMMs) with Gaussian variance and identity link functions were used to estimate the confounder-adjusted associations between objectively-assessed physical neighbourhood attributes and QoL domains. GAMMs can model outcomes with various distributional assumptions, spatially correlated data and curvilinear relationships of unknown form [39].

First, a set of GAMMs estimated the associations of all covariates and living arrangements with QoL domain scores. Another set of main-effect GAMMs estimated the dose-response relationships of single environmental variables with QoL domain scores. Curvilinear relationships of environmental variables with the outcomes were assessed with thin-plate smoothing spline terms in GAMMs. Thin-plate splines are a type of smoothing splines that are used to model and visualize complex curvilinear relationships between continuous exposure and outcome variables. Their advantage over other smoothing spline methods is that they do not require any a priori knowledge of the functional form of the relationship of interest [39]. Smooth terms failing to provide sufficient evidence of curvilinearity, defined as a 5-unit difference in Akaike Information Criterion between a GAMM with an exposure modelled using a thin-plate spline and a GAMM with the same exposure modelled using a linear term, were replaced by simpler linear terms [39]. Moderating effects of environmental attributes on the associations between living arrangements and QoL were estimated by adding two-way interaction terms to the main-effect GAMMs. Significant interactions $(p<0.05)$ were probed using Johnson-Neyman procedures, whereby we estimated the region of significance of moderators, i.e., the range of values of the environmental attributes for which the effects of living arrangements (living alone vs. living with others) on QoL domain scores were statistically significant. 
All single environmental attributes and interaction terms with $p$-value $<0.10$ were entered in multiple-environmental-variable GAMMs adjusted for all covariates. We adopted a probability level of 0.10 as a criterion for the preliminary selection of environmental attributes and interaction terms to be included in multiple-environmental-variable models in order to avoid missing potentially important explanatory variables due to negative confounding. Environmental attributes that were strongly correlated were combined into composite variables as appropriate. Only those environmental attributes and interaction terms that showed a significant independent effect on the outcomes $(p<0.05)$ were retained in the final multiple-environmental-variable models. Following the recommendations of statistical theorists, no adjustments for multiple testing were performed because the analyses were confirmatory and the outcomes and environmental exposures were correlated [40,41]. All analyses were conducted in $\mathrm{R}$ using the packages "mgcv" and "gmodels" [42,43].

\section{Results}

Table 1 summarises the characteristics of the sample. Nearly a quarter of the sample reported living alone. Substantial levels of variability across residential buffers were observed for most of the examined environmental attributes except for signs of crime/disorder. Overall, residential buffers scored low on the presence of signs of crime/disorder and stray dogs/animals and relatively high on residential density, traffic safety, pedestrian infrastructure, presence of people, pollution and several destination-related measures.

Table 1. Sample characteristics $(N=909)$.

\begin{tabular}{|c|c|}
\hline Variables [Theoretical Range] & Statistics (\%) \\
\hline \multicolumn{2}{|l|}{ Socio-demographic and health-related characteristics } \\
\hline Sex, females & 66.3 \\
\hline \multicolumn{2}{|l|}{ Educational attainment } \\
\hline No formal education & 20.8 \\
\hline Primary school & 35.5 \\
\hline Secondary school & 30.5 \\
\hline Post-secondary school & 13.2 \\
\hline \multicolumn{2}{|l|}{ Marital status } \\
\hline Married or cohabiting & 59.5 \\
\hline Widowed & 32.7 \\
\hline Other & 7.8 \\
\hline \multicolumn{2}{|l|}{ Housing } \\
\hline Public and aided & 43.1 \\
\hline Private (purchased) & 51.3 \\
\hline Renting & 5.6 \\
\hline Living alone & 23.1 \\
\hline Household with car & 28.5 \\
\hline \multicolumn{2}{|l|}{ Type of recruitment centre } \\
\hline Elderly health centres & 82.6 \\
\hline Elderly community centres & 28.4 \\
\hline \multicolumn{2}{|l|}{ Neighbourhood type } \\
\hline Low walkable, low SES & 22.0 \\
\hline Low walkable, high SES & 24.8 \\
\hline High walkable, low SES & 28.3 \\
\hline \multirow[t]{2}{*}{ High walkable, high SES } & 25.0 \\
\hline & Median (IQR) $^{a}$ \\
\hline Age (years) & $76.5(6.0)$ \\
\hline Number of diagnosed health problems [0-10] & $3.2(2.0)$ \\
\hline \multicolumn{2}{|l|}{ Outcome: quality of life } \\
\hline Domain 1: Physical health (score) [4-20] & $16.1(2.4)$ \\
\hline Domain 2: Psychological health (score) [4-20] & $16.5(2.1)$ \\
\hline Domain 3: Social relationships (score) [4-20] & $15.1(2.1)$ \\
\hline Domain 4: Environment (score) [4-20] & $17.0(2.0)$ \\
\hline
\end{tabular}


Table 1. Cont.

\begin{tabular}{|c|c|c|c|}
\hline \multicolumn{2}{|l|}{ Variables [Theoretical Range] } & \multicolumn{2}{|c|}{ Statistics (\%) } \\
\hline Environmental attributes & \multicolumn{2}{|c|}{ Buffer } & \\
\hline \multicolumn{4}{|c|}{ Based on extant GIS data aggregated by street-network residential buffers } \\
\hline \multirow{2}{*}{ Gross residential density $\left(1000\right.$ households $/ \mathrm{km}^{2}$ ) } & $400 \mathrm{~m}$ & $15.8(11.2)$ & $12.2(13.8)$ \\
\hline & $800 \mathrm{~m}$ & $14.3(8.4)$ & $12.9(11.4)$ \\
\hline \multirow{2}{*}{ Street intersection density (intersections $/ \mathrm{km}^{2}$ ) } & $400 \mathrm{~m}$ & $119.9(58.0)$ & \\
\hline & $800 \mathrm{~m}$ & $91.5(40.0)$ & \\
\hline \multirow{2}{*}{ Civic and institutional density (destinations $/ \mathrm{km}^{2}$ ) } & $400 \mathrm{~m}$ & $88.2(53.8)$ & \\
\hline & $800 \mathrm{~m}$ & $69.7(36.5)$ & \\
\hline \multirow{2}{*}{ Entertainment density (destinations $/ \mathrm{km}^{2}$ ) } & $400 \mathrm{~m}$ & $11.8(16.9)$ & $7.3(16.1)$ \\
\hline & $800 \mathrm{~m}$ & $6.9(5.2)$ & $6.2(6.2)$ \\
\hline \multirow{2}{*}{ Recreation density (destinations $/ \mathrm{km}^{2}$ ) } & $400 \mathrm{~m}$ & $21.2(23.2)$ & $17.5(30.5)$ \\
\hline & $800 \mathrm{~m}$ & $22.5(15.2)$ & $20.1(13.6)$ \\
\hline \multirow{2}{*}{ Park area (hectares) } & $400 \mathrm{~m}$ & $1.6(9.4)$ & $0.2(0.9)$ \\
\hline & $800 \mathrm{~m}$ & $9.5(59.1)$ & $2.0(5.3)$ \\
\hline \multicolumn{4}{|c|}{ Based on environmental audit data aggregated by crow-fly residential buffers } \\
\hline Connectivity (score) $(0-100)$ & $400 \mathrm{~m}$ & $40.6(7.4)$ & \\
\hline Prevalence of non-food retail and services (number) & $400 \mathrm{~m}$ & $15.9(16.5)$ & $11.0(19.0)$ \\
\hline Prevalence of food-related shops (number) & $400 \mathrm{~m}$ & $10.2(8.6)$ & $11.0(19.0)$ \\
\hline Prevalence of eating outlets (number) & $400 \mathrm{~m}$ & $13.6(13.1)$ & $9.0(18.0)$ \\
\hline Prevalence of destinations for socialising (number) & $400 \mathrm{~m}$ & $6.5(6.2)$ & $5.0(7.0)$ \\
\hline Prevalence of health clinics/services (number) & $400 \mathrm{~m}$ & $3.9(4.2)$ & $3.0(4.0)$ \\
\hline Prevalence of public transport stops (number) & $400 \mathrm{~m}$ & $8.1(4.7)$ & $7.0(5.0)$ \\
\hline Number of parks & $400 \mathrm{~m}$ & $2.7(2.4)$ & $2.0(2.0)$ \\
\hline Activity types in park (score) & $400 \mathrm{~m}$ & $1.8(1.7)$ & $2.0(3.0)$ \\
\hline Amenities in park (score) [0-7] & $400 \mathrm{~m}$ & $2.9(1.4)$ & \\
\hline Trees in park (score) [0-5] & $400 \mathrm{~m}$ & $2.1(1.2)$ & \\
\hline Paths in park (score) [0-6] & $400 \mathrm{~m}$ & $1.7(1.3)$ & $2.0(1.0)$ \\
\hline Park aesthetics (score) [0-3] & $400 \mathrm{~m}$ & $2.4(1.0)$ & \\
\hline Park visibility (score) [2-6] & $400 \mathrm{~m}$ & $2.1(1.0)$ & \\
\hline Pedestrian infrastructure (score) [0-100] & $400 \mathrm{~m}$ & $62.7(9.4)$ & \\
\hline Sitting facilities (score) $[0-100]$ & $400 \mathrm{~m}$ & $20.5(20.1)$ & $17.0(31.0)$ \\
\hline Crowdedness (score) [0-100] & $400 \mathrm{~m}$ & $9.8(8.8)$ & $7.7(12.5)$ \\
\hline Presence of people (score) [0-100] & $400 \mathrm{~m}$ & $64.5(21.6)$ & \\
\hline Traffic safety (score) [0-100] & $400 \mathrm{~m}$ & $69.9(15.0)$ & \\
\hline Greenery/natural sights (score) [0-100] & $400 \mathrm{~m}$ & $36.9(16.7)$ & $45.5(25.6)$ \\
\hline Signs of crime/disorder (score) [0-100] & $400 \mathrm{~m}$ & $0.3(0.9)$ & $0.0(0.0)$ \\
\hline Stray dogs/animals (score) [0-100] & $400 \mathrm{~m}$ & $5.9(9.9)$ & $0.0(9.0)$ \\
\hline Litter/decay (score) [0-100] & $400 \mathrm{~m}$ & $22.9(4.1)$ & \\
\hline Pollution (score) [0-100] & $400 \mathrm{~m}$ & $42.3(33.2)$ & $40.0(61.2)$ \\
\hline Number of street segments audited & $400 \mathrm{~m}$ & $21.4(17.5)$ & $16.0(13.0)$ \\
\hline
\end{tabular}

$\mathrm{SES}=$ socio-economic status; $\mathrm{SD}$ = standard deviation; $\mathrm{IQR}=$ interquartile range; GIS geographic information systems; ${ }^{a}$ computed for environmental variables with skewness $>|1.0|$.

Associations of QoL domains with socio-demographics and health conditions are shown in Table S2. Males reported higher physical and psychological QoL but lower social QoL than females. Educational attainment was positively related to all QoL domains. Widowed elders reported higher environmental QoL than those who never married or were separated/divorced. Higher environmental QoL was also reported among those having a car in their household than their counterparts. Older adults having more health problems reported lower levels of physical, psychological and social QoL.

Table 2 summarises the associations between single neighbourhood environmental attributes and QoL domains. As GIS measures of the environment based on $400 \mathrm{~m}$ buffers yielded weaker associations with QoL than those based on $800 \mathrm{~m}$ buffers, only the latter are presented in Table 2, while the former are reported in Table S3. No significant associations were found between the examined environmental attributes and physical QoL. Gross residential density was curvilinearly associated with environmental QoL only, whereby a positive association was found in those living in areas between 10,000 and 23,000 households $/ \mathrm{km}^{2}$ (Figure S1, right top), while residents of areas $<10,000$ and $>23,000$ households $/ \mathrm{km}^{2}$ showed nil or slightly negative associations. Entertainment density was curvilinearly associated with both psychological and environmental QoL. For psychological QoL, 
there was a positive association below 5 destinations $/ \mathrm{km}^{2}$ followed by a negative association until approximately 16 destinations $/ \mathrm{km}^{2}$. At $>16$ destinations $/ \mathrm{km}^{2}$, the association was weak (large $95 \%$ confidence intervals due to a low number of observations) and showing a positive trend (Figure S1, left bottom). A similar dose-response relationship was found for environmental QoL (Figure S1, right bottom). Entertainment density within $800 \mathrm{~m}$ buffers was also negatively, linearly associated with social QoL (Table 2). Street intersection density was negatively associated with both environmental and social QoL. The numbers of parks and activity types in parks were both negatively associated with social QoL, while the (maximum) prevalence of trees in parks was positively associated with social QoL. Density/prevalence of other types of services/destinations, connectivity, park area, pedestrian infrastructure, sitting facilities, crowdedness, presence of people and various measures of environmental aesthetics and safety were not significantly associated with any QoL domain in the whole sample.

The moderating effects of neighbourhood environmental attributes on the associations between living arrangements and QoL are summarised in Table 3, where we report the ranges of values of the environmental attributes for which the associations between living arrangements and QoL were significant at a probability level of 0.05 . Compared to those living with others, older adults living alone reported lower environmental QoL when residing in neighbourhoods with poor access to non-food retail/services, food-related shops, eating outlets, health clinic/services, destinations suitable for socialising, civic/institutional destinations, fewer parks and lower levels of desirable park attributes (i.e., activity types, trees, paths and aesthetics). In contrast, when residing in neighbourhoods with more parks and activity types in parks, participants living alone reported higher environmental and social QoL than their counterparts. At high levels of greenery/natural sights ( $\geq 51.8$ points), participants living alone reported lower social QoL than their counterparts. Compared to those living with others, participants living alone reported higher psychological QoL if residing in neighbourhoods with some signs of crime/disorder, while they reported lower physical QoL if living in neighbourhoods with larger park areas ( $\geq 58.8$ hectares, at $\sim 98.5$ th percentile). Environmental attributes that did not moderate the relationship of living arrangements with any QoL domain were: residential density, street intersection density, connectivity, entertainment density, recreation density, prevalence of public transport stops, amenities in parks, park visibility, pedestrian infrastructure, sitting facilities, crowdedness, presence of people, traffic safety, litter/decay, pollution and the presence of stray dogs/animals.

In multiple-neighbourhood-attribute models (Table 4), all curvilinear associations of gross residential density and entertainment density with QoL domains remained significant. The patterns of these relationships (Figure 1) resembled those of the single-neighbourhood-attribute models (Figure S1). As for linear relationships, the associations of street intersection density with environmental QoL and those of entertainment density, number of parks and park trees with social QoL remained significant. The negative association of presence of litter/decay with environmental QoL became stronger in the multiple attribute model. The neighbourhood attributes that remained significant moderators of the associations between living arrangements and QoL domains were: park area within $800 \mathrm{~m}$ buffers for physical QoL; signs of crime/disorder for psychological QoL; activity types in park for social QoL; and a composite destination index (a summed z-score of correlated destination attributes) for environmental QoL. 
Table 2. Associations of single neighbourhood physical environmental attributes with quality of life (QoL) domains.

\begin{tabular}{|c|c|c|c|c|c|c|c|c|}
\hline \multirow{2}{*}{ Environmental Attributes (Unit) } & \multicolumn{2}{|l|}{ Physical QoL } & \multicolumn{2}{|c|}{ Psychological QoL } & \multicolumn{2}{|l|}{ Social QoL } & \multicolumn{2}{|l|}{ Environmental QoL } \\
\hline & $b(95 \% C I)$ & $p$ & $b(95 \% C I)$ & $p$ & $b(95 \% C I)$ & $p$ & $b(95 \% C I)$ & $p$ \\
\hline Gross residential density a (1000 households $/ \mathrm{km}^{2}$ ) & $-0.007(-0.028,0.013)$ & 0.485 & $0.011(-0.006,0.028)$ & 0.217 & $-0.001(-0.018,0.016)$ & 0.914 & $-0.696(-1.419,0.027)$ & 0.059 \\
\hline- Curvilinear $^{+}$ & - & - & - & - & - & - & $F_{(3.318,3.318)}=2.847^{*}$ & 0.029 \\
\hline $\begin{array}{l}\text { Street intersection density }{ }^{a} \\
\left(100 \text { intersections } / \mathrm{km}^{2}\right)\end{array}$ & $-0.138(-0.576,0.300)$ & 0.537 & $-0.325(-0.685,0.034)$ & 0.076 & $-0.396(-0.744,-0.047) *$ & 0.026 & $-0.731(-1.083,-0.379)^{* * *}$ & $<0.001$ \\
\hline Connectivity ${ }^{\mathrm{b}}$ (score) & $-0.001(-0.027,0.025)$ & 0.945 & $-0.001(-0.022,0.021)$ & 0.962 & $0.005(-0.016,0.026)$ & 0.646 & $0.003(-0.018,0.024)$ & 0.781 \\
\hline $\begin{array}{l}\text { Civic and institutional density a } \\
\left(\text { destinations } / \mathrm{km}^{2}\right)\end{array}$ & $0.001(-0.004,0.006)$ & 0.663 & $0.000(-0.003,0.004)$ & 0.818 & $-0.002(-0.006,0.002)$ & 0.258 & $-0.003(-0.006,0.001)$ & 0.206 \\
\hline Prevalence of non-food retail/services ${ }^{b}$ (number) & $-0.004(-0.016,0.009)$ & 0.572 & $-0.008(-0.018,0.002)$ & 0.130 & $-0.008(-0.018,0.003)$ & 0.143 & $-0.005(-0.015,0.005)$ & 0.332 \\
\hline Entertainment density a (destinations $/ \mathrm{km}^{2}$ ) & $-0.015(-0.047,0.017)$ & 0.369 & $0.512(-0.277,1.301)$ & 0.203 & $-0.042(-0.068,-0.016) * *$ & 0.002 & $0.528(-0.248,1.30)$ & 0.182 \\
\hline- Curvilinear $^{\dagger}$ & - & 0.00 & $F_{(3.572,3.572)}=3.332 * *$ & 0.009 & 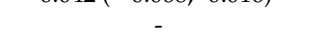 & - & $F_{(3652.3652)}=3.706^{* *}$ & 0.004 \\
\hline Recreation density a (destination $/ \mathrm{km}^{2}$ ) & $-0.008(-0.019,0.003)$ & 0.152 & $-0.002(-0.011,0.007)$ & 0.679 & $-0.001(-0.010,0.008)$ & 0.861 & $0.000(-0.009,0.009)$ & 0.988 \\
\hline Prevalence of food-related shops ${ }^{b}$ (number) & $-0.015(-0.040,0.011)$ & 0.257 & $-0.013(-0.033,0.007)$ & 0.198 & $-0.016(-0.036,0.003)$ & 0.100 & $0.001(-0.020,0.022)$ & 0.929 \\
\hline Prevalence of eating outlets ${ }^{b}$ (number) & $-0.000(-0.019,0.018)$ & 0.971 & $-0.004(-0.019,0.011)$ & 0.626 & $-0.002(-0.017,0.013)$ & 0.774 & $0.001(-0.014,0.016)$ & 0.928 \\
\hline Prevalence of destinations for socialising $\mathrm{b}$ (number) & $-0.012(-0.045,0.022)$ & 0.494 & $-0.010(-0.037,0.018)$ & 0.497 & $-0.016(-0.042,0.011)$ & 0.243 & $-0.005(-0.032,0.023)$ & 0.737 \\
\hline Prevalence of health clinics/services ${ }^{b}$ (number) & $-0.006(-0.052,0.039)$ & 0.788 & $-0.018(-0.056,0.019)$ & 0.335 & $-0.029(-0.066,0.007)$ & 0.111 & $-0.000(-0.037,0.037)$ & 0.996 \\
\hline Prevalence of public transport stops ${ }^{b}$ (number) & $-0.024(-0.074,0.026)$ & 0.355 & $-0.002(-0.043,0.039)$ & 0.927 & $-0.026(-0.065,0.013)$ & 0.194 & $0.003(-0.037,0.044)$ & 0.875 \\
\hline Parks ${ }^{b}$ (number) & $-0.031(-0.100,0.038)$ & 0.383 & $-0.045(-0.101,0.012)$ & 0.123 & $-0.080(-0.135,-0.025)^{* *}$ & 0.005 & $-0.026(-0.085,0.034)$ & 0.398 \\
\hline Park area ${ }^{\mathrm{a}}$ (hectares) & $-0.000(-0.003,0.002)$ & 0.852 & $0.000(-0.002,0.002)$ & 0.998 & $-0.002(-0.004,-0.000)$ & 0.112 & $0.000(-0.002,0.003)$ & 0.776 \\
\hline Activity types in park ${ }^{\mathrm{b}}$ (number) & $-0.031(-0.127,0.066)$ & 0.537 & $-0.018(-0.098,0.062)$ & 0.657 & $-0.096(-0.175,-0.018)^{*}$ & 0.016 & $-0.044(-0.127,0.039)$ & 0.296 \\
\hline Amenities in park ${ }^{b}$ (score) & $-0.049(-0.175,0.077)$ & 0.448 & $0.006(-0.100,0.112)$ & 0.911 & $0.043(-0.060,0.147)$ & 0.414 & $-0.006(-0.114,0.103)$ & 0.918 \\
\hline Trees in park ${ }^{b}$ (score) & $0.074(-0.085,0.233)$ & 0.359 & $0.053(-0.080,0.186)$ & 0.439 & $0.132(0.003,0.261) *$ & 0.046 & $-0.018(-0.154,0.118)$ & 0.799 \\
\hline Paths in park ${ }^{b}$ (score) & $0.072(-0.083,0.226)$ & 0.362 & $0.062(-0.067,0.192)$ & 0.347 & $0.046(-0.080,0.173)$ & 0.470 & $0.006(-0.126,0.137)$ & 0.934 \\
\hline Park aesthetics ${ }^{b}$ (score) & $-0.031(-0.210,0.148)$ & 0.734 & $-0.003(-0.154,0.147)$ & 0.964 & $0.087(-0.060,0.234)$ & 0.243 & $0.052(-0.102,0.205)$ & 0.509 \\
\hline Park visibility ${ }^{\mathrm{b}}$ (score) & $-0.022(-0.217,0.173)$ & 0.823 & $-0.016(-0.178,0.145)$ & 0.843 & $0.131(-0.026,0.288)$ & 0.102 & $0.022(-0.145,0.190)$ & 0.792 \\
\hline Pedestrian infrastructure ${ }^{\mathrm{b}}$ (score) & $0.008(-0.013,0.028)$ & 0.462 & $0.001(-0.015,0.016)$ & 0.938 & $0.004(-0.012,0.019)$ & 0.647 & $0.010(-0.006,0.026)$ & 0.220 \\
\hline Sitting facilities ${ }^{b}$ (score) & $-0.004(-0.015,0.006)$ & 0.418 & $-0.003(-0.011,0.005)$ & 0.397 & $0.001(-0.007,0.009)$ & 0.770 & $-0.002(-0.010,0.006)$ & 0.614 \\
\hline Crowdedness ${ }^{b}$ (score) & $-0.016(-0.036,0.005)$ & 0.131 & $-0.010(-0.027,0.006)$ & 0.218 & $-0.010(-0.026,0.006)$ & 0.228 & $-0.005(-0.021,0.012)$ & 0.567 \\
\hline Presence of people ${ }^{b}$ (score) & $-0.005(-0.014,0.004)$ & 0.248 & $0.000(-0.007,0.008)$ & 0.927 & $-0.003(-0.011,0.004)$ & 0.394 & $0.000(-0.007,0.008)$ & 0.915 \\
\hline Traffic safety ${ }^{b}$ (score) & $0.000(-0.012,0.013)$ & 0.968 & $0.002(-0.008,0.013)$ & 0.655 & $-0.002(-0.013,0.008)$ & 0.628 & $0.004(-0.007,0.014)$ & 0.484 \\
\hline Greenery/natural sights ${ }^{b}$ (score) & $-0.005(-0.023,0.013)$ & 0.565 & $-0.007(-0.022,0.008)$ & 0.377 & $-0.001(-0.015,0.014)$ & 0.909 & $0.004(-0.011,0.019)$ & 0.079 \\
\hline Signs of crime/disorder ${ }^{b}$ (score) & $-0.023(-0.221,0.176)$ & 0.823 & $-0.084(-0.246,0.077)$ & 0.306 & $-0.080(-0.238,0.078)$ & 0.322 & $-0.020(-0.183,0.143)$ & 0.808 \\
\hline Stray dogs/animals ${ }^{\mathrm{b}}$ (score) & $-0.009(-0.028,0.009)$ & 0.320 & $-0.008(-0.023,0.007)$ & 0.291 & $-0.000(-0.015,0.014)$ & 0.992 & $-0.002(-0.017,0.013)$ & 0.794 \\
\hline Litter/decay ${ }^{b}$ (score) & $-0.011(-0.056,0.034)$ & 0.632 & $-0.035(-0.070,0.000)$ & 0.053 & $-0.031(-0.065,0.004)$ & 0.080 & $-0.035(-0.071,0.001)$ & 0.059 \\
\hline Pollution ${ }^{b}$ (score) & $-0.000(-0.006,0.005)$ & 0.902 & $-0.002(-0.006,0.003)$ & 0.459 & $-0.003(-0.008,0.001)$ & 0.112 & $-0.003(-0.007,0.002)$ & 0.234 \\
\hline
\end{tabular}

$b=$ regression coefficient; $\mathrm{CI}=$ confidence interval; $p=p$-value; - = not applicable. ${ }^{\text {a }}$ based on extant geographic information systems data - measure computed using $800 \mathrm{~m}$ street-network residential buffers; ${ }^{\mathrm{b}}$ based on data from environmental audits-measure computed using $400 \mathrm{~m}$ crow-fly residential buffers; ${ }^{\dagger}$ curvilinear associations depicted in Figure $\mathrm{S} 1$

(Additional file 1). All estimates adjusted for age, sex, educational attainment, household with car, marital status, housing type, living arrangement, area-level socio-economic status, type

of recruitment centre, and number of current diagnosed health problems. "0.000" occurs due to rounding and does not equal to zero. ${ }^{*} p<0.05 ;{ }^{* *} p<0.01 ;{ }^{* * *} p<0.001$. 
Table 3. Associations between living arrangements (reference group: living with others) and quality of life (QoL) domains at region-of-significance threshold values of neighbourhood physical environmental attributes (moderators).

\begin{tabular}{|c|c|c|c|}
\hline Environmental Attribute & QoL Domain & $\begin{array}{l}\text { Region-of-Significance Value of Environmental } \\
\text { Moderator [\% SRSV] }\end{array}$ & $b(95 \% C I)$ \\
\hline Civic and institutional density ${ }^{a}$ & Environmental & $\leq 44.0$ locations $/ \mathrm{km}^{2}[23 \%]$ & $-0.405(-0.809,-0.000) *$ \\
\hline Prevalence of non-food retail/services ${ }^{b}$ & Environmental & $\leq 1.3$ destinations $/$ bf $[14 \%]$ & $-0.446(-0.892,-0.000) *$ \\
\hline Prevalence of food-related shops ${ }^{b}$ & Environmental & $\leq 4.0 \mathrm{shops} / \mathrm{bf}[35 \%]$ & $-0.441(-0.821,-0.002) *$ \\
\hline Prevalence of eating outlets $\mathrm{b}$ & Environmental & $\leq 1.4$ outlets $/$ bf $[14 \%]$ & $-0.443(-0.884,-0.001) *$ \\
\hline Prevalence of destinations for socialising ${ }^{b}$ & Environmental & $\leq 0.8$ destinations $/$ bf $[9 \%]$ & $-0.446(-0.892,0.000)$ * \\
\hline Prevalence of health clinics/services ${ }^{b}$ & Environmental & $\begin{array}{l}\leq 1.6 \text { destinations } / \mathrm{bf}[35 \%] \\
\geq 11.6 \text { destinations } / \mathrm{bf}[8 \%]\end{array}$ & $\begin{array}{c}-0.388(-0.773,-0.004)^{*} \\
0.693(0.004,1.383)^{*}\end{array}$ \\
\hline Number of parks ${ }^{b}$ & $\begin{array}{c}\text { Social } \\
\text { Environmental }\end{array}$ & $\begin{array}{l}\leq 0.9 \text { parks } / \mathrm{bf}[13 \%] \\
\geq 11.7 \text { parks } / \mathrm{bf}[2 \%] \\
\leq 1.3 \text { parks } / \mathrm{bf}[25 \%] \\
\geq 10.2 \text { parks } / \mathrm{bf}[2 \%]\end{array}$ & $\begin{array}{c}-0.429(-0.850,-0.008)^{*} \\
1.176(0.002,2.351)^{*} \\
-0.390(-0.773,-0.006) * \\
0.962(0.000,1.923)^{*}\end{array}$ \\
\hline Park area ${ }^{a}$ & $\begin{array}{c}\text { Physical } \\
\text { Psychological }^{\dagger}\end{array}$ & $\begin{array}{c}\geq 58.8 \text { hectares }[2 \%] \\
\text { Minimum: } 0 \text { types }[69 \%] \\
\text { Maximum: } 9 \text { types }[2 \%]\end{array}$ & $\begin{array}{c}-0.913(-1.825,-0.000)^{*} \\
-0.392(-0.880,0.097)^{\#} \\
1.289(-0.101,2.678)\end{array}$ \\
\hline Activity types in park ${ }^{\mathrm{b}}$ & $\begin{array}{c}\text { Social } \\
\text { Environmental }\end{array}$ & $\begin{array}{l}\leq 0.8 \text { types } / \mathrm{bf}[31 \%] \\
\geq 5.6 \text { types } / \mathrm{bf}[3 \%] \\
\leq 0.8 \text { types } / \mathrm{bf}[31 \%] \\
\geq 7.3 \text { types } / \mathrm{bf}[2 \%]\end{array}$ & $\begin{array}{c}-0.412(-0.810,-0.013) * \\
0.785(0.001,1.568)^{*} \\
-0.388(-0.771,-0.006) * \\
1.026(0.005,2.046)^{*}\end{array}$ \\
\hline Trees in park $b$ & Environmental & $\leq 1.3$ points $[18 \%]$ & $-0.419(-0.822,-0.016) *$ \\
\hline Paths in park ${ }^{b}$ & Environmental & $\leq 0.7$ points $[14 \%]$ & $-0.427(-0.845,-0.008) *$ \\
\hline Park aesthetics ${ }^{b}$ & Environmental & $\leq 1.9$ points $[13 \%]$ & $-0.427(-0.834,-0.019)$ * \\
\hline Greenery/natural sights ${ }^{b}$ & Social & $\geq 51.8$ points $[3 \%]$ & $-0.454(-0.908,-0.000) *$ \\
\hline Signs of crime/disorder ${ }^{b}$ & Psychological & $\geq 2.0$ points $[7 \%]$ & $0.752(0.013,1.492) *$ \\
\hline
\end{tabular}

Notes. $b=$ regression coefficient; $C I=$ confidence interval; $\% \mathrm{SRS}=\%$ of sample falling within the region of significance values. ${ }^{a}$ based on extant geographic information systems data - measure computed using $800 \mathrm{~m}$ street-network residential buffers; ${ }^{b}$ based on data from environmental audits-measure computed using $400 \mathrm{~m}$ crow-fly residential buffer. bf $=$ buffer. + Given no region-of-significance found, estimates at minimum and maximum values of moderator are shown. All estimates adjusted for age, gender, educational attainment, household with car, marital status, housing type, area-level socio-economic status, type of recruitment centre, and number of current diagnosed health problems. "0.000" occurs due to rounding and does not equal to zero. Only significant $(p<0.05)$ interaction terms between living arrangements and specific neighbourhood environmental attributes are shown. * $p=0.050$; $\# p=0.116 ; \ddagger p=0.069$. 
Table 4. Associations of multiple neighbourhood physical environmental attributes with quality of life (QoL) domains.

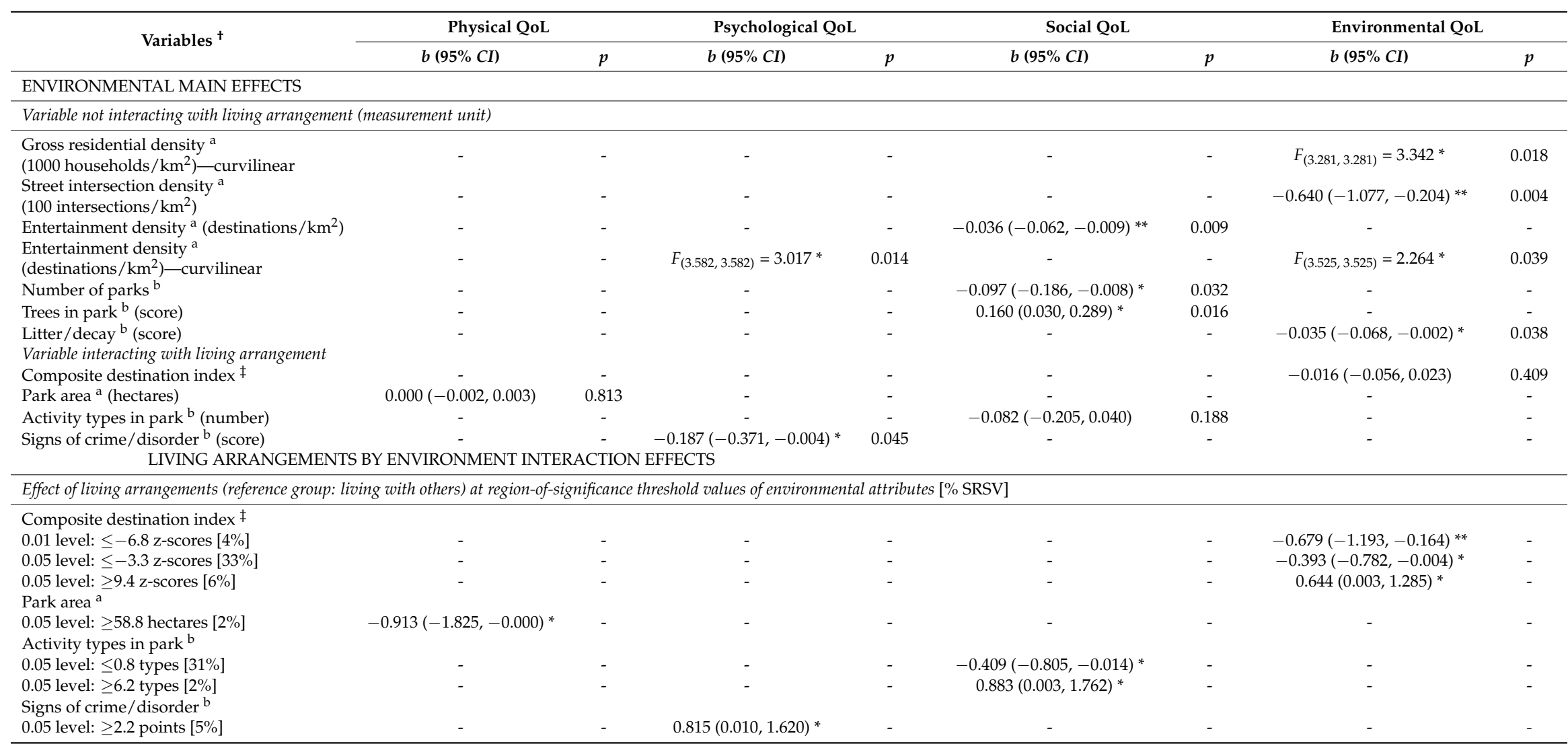

Notes. $b=$ regression coefficient; $C I=$ confidence interval; $p=p$-value; .05 or .01 level $=$ significance levels; $-=$ not applicable; $\%$ SRS $=\%$ of sample falling within the region of significance values. ${ }^{a}$ based on extant geographic information systems data-measure computed using $800 \mathrm{~m}$ street-network residential buffers; ${ }^{\mathrm{b}}$ based on data from environmental audits-measure computed using $400 \mathrm{~m}$ crow-fly residential buffer. ${ }^{\dagger}$ associations were linear unless specified, and curvilinear associations are depicted in Figure $1 .{ }^{\ddagger}$ the sum of z-scores of single destination-related variables that interacted with living arrangement in the single-environmental-variable models, including civic and institutional density- $800 \mathrm{~m}$ street-network buffer, prevalence of non-food retail/services, prevalence of food-related shops, prevalence of eating outlets, prevalence of destinations for socialising, and prevalence of health clinics/services. All estimates adjusted for age, gender, educational attainment, household with car, marital status, housing type, area-level socio-economic status, type of recruitment centre, number of current diagnosed health problems, and other environmental attributes that uniquely contributed to the explanation of the outcome variables through main or moderating effects. "0.000" occurs due to rounding and does not equal to zero. ${ }^{*} p<0.05 ;{ }^{* *} p<0.01$. 


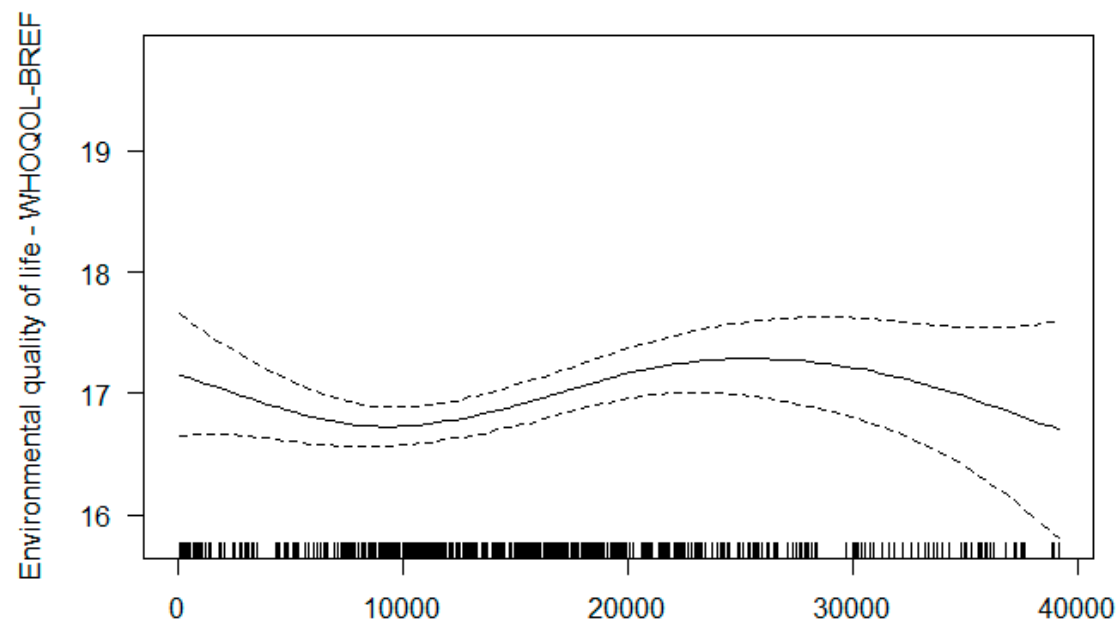

Gross residential density (households/sq.km) - $800 \mathrm{~m}$ buffers

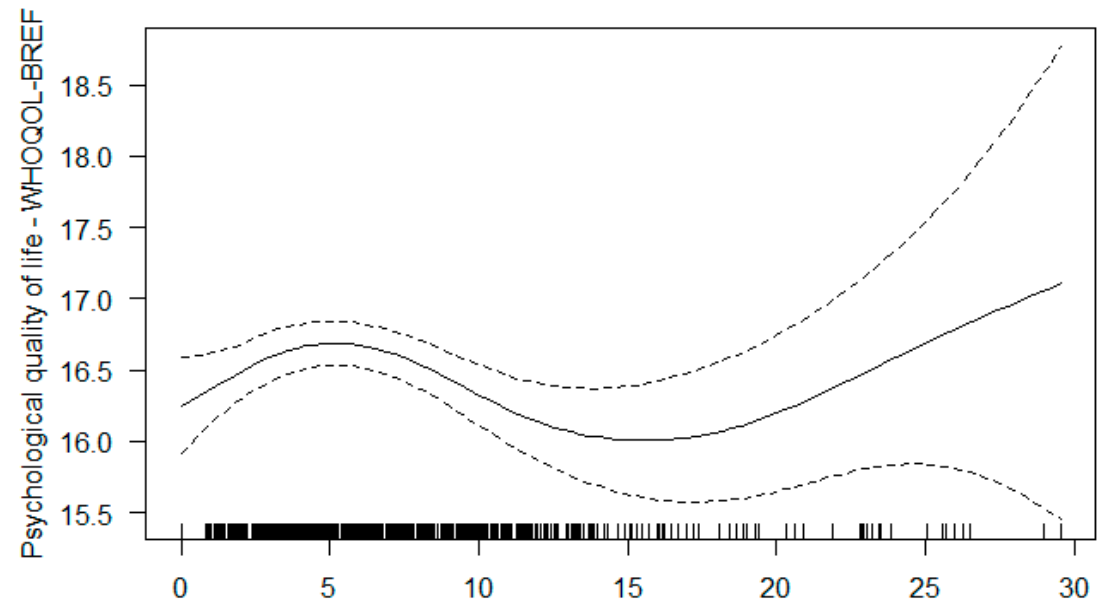

Entertainment density (destinations/sq.km) - $800 \mathrm{~m}$ buffers

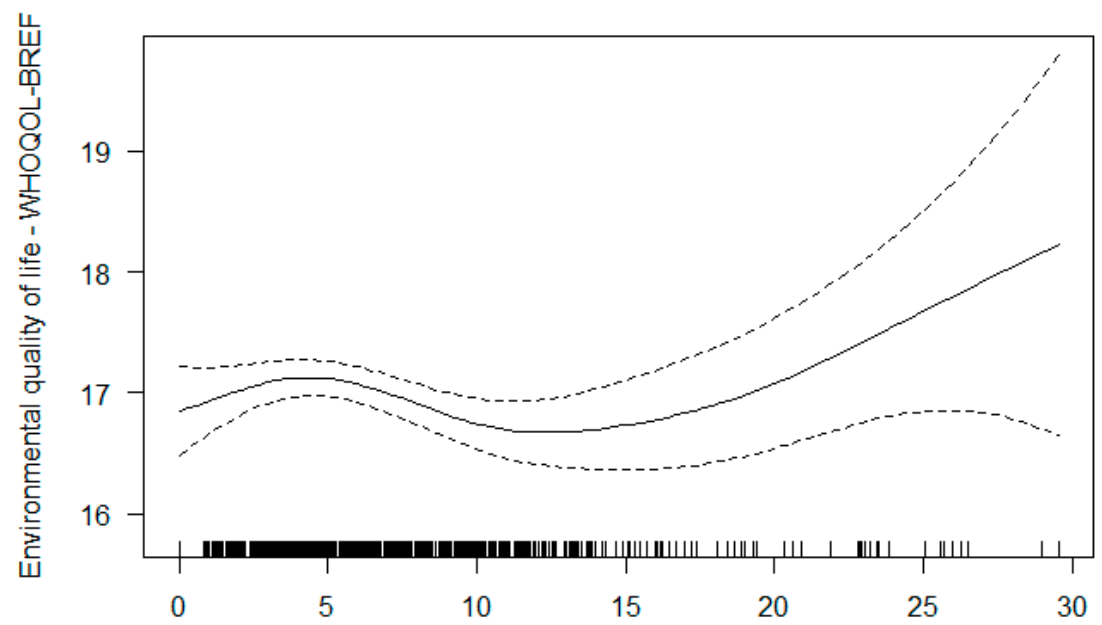

Entertainment density (destinations/sq.km) - $800 \mathrm{~m}$ buffers

Figure 1. Independent curvilinear associations of neighbourhood physical attributes with quality of life (QoL). [Full lines represent point estimates of modelled scores of specific QoL dimensions, while the dotted lines represent their $95 \%$ confidence intervals.]. 


\section{Discussion}

Safe, green, aesthetically-pleasing neighbourhoods with a variety of daily destinations and services and a good-quality pedestrian infrastructure are thought to contribute to older adults' QoL $[3,21,44]$. These neighbourhood characteristics are likely to be particularly important to older residents who live alone as they provide opportunities for engagement in social activities and can help them maintain their independence in activities of daily living [4,6-8]. Overall, this study provides partial support for these hypotheses in relation to environmental and, somewhat, social QoL, but not with respect to physical and psychological QoL.

Although very few significant associations were observed between objectively-assessed neighbourhood attributes and environmental QoL in the whole sample, most measures of destination accessibility and several measures of park quality (e.g., trees and number of park activities) modified the negative effects of living alone on environmental QoL in the expected direction. Older adults who had poor access to retail, eateries, health-related services, places for socialising, civic/institutional destinations and good-quality parks reported lower levels of environmental QoL if living alone than if living with others. These findings suggest that these neighbourhood attributes are particularly important to older residents who live alone, enabling self-reliance in performing activities of daily living. Although to our knowledge no other study has examined neighbourhood characteristics as moderators of living arrangements-QoL associations, a recent survey of Dutch elderly reported that perceived access to facilities was positively related to environmental QoL, providing further support for the importance of neighbourhood destination accessibility to older residents' satisfaction with the environment [45].

Whilst no significant positive associations between environmental QoL and access to single destination categories were found in the whole sample, we observed a curvilinear relationship with residential density suggestive of a positive association for values ranging from $\sim 9000$ to 23,000 dwellings $/ \mathrm{km}^{2}$ (corresponding to the samples' 25th and 87th percentiles of density) and a nil or slightly negative association thereafter. As residential density is necessary to support local commercial and public services, it is a proxy measure of overall destination accessibility. Medium-to-high density neighbourhoods are generally characterised by mixed-use developments with a large range of complementary destinations that offer opportunities for utilitarian walking and social activities $[30,46]$. However, extreme levels of density are often accompanied by excessive pollution, crowding and noise [47], which may, in turn, negatively affect residents' environmental QoL [48].

Entertainment density was the only other destination-related variable to show a significant relationship with environmental QoL in the whole sample, suggesting a positive effect for values below 5 destinations $/ \mathrm{km}^{2}$ (40th percentile) and a negative effect for values ranging from 5 to 13 destinations $/ \mathrm{km}^{2}$ (89th percentile) (Figure 1). A similarly-shaped relationship was also observed in relation to psychological QoL, whilst a negative linear association was found with social QoL. Neighbourhoods with several diverse entertainment destinations (e.g., a cinema, a museum and a community centre) may provide access to interesting cultural and intellectual activities that may enhance older residents' psychological well-being and satisfaction with the environment. However, neighbourhoods with a high concentration of entertainment destinations may not provide sufficient access to other types of destination important for daily living and social QoL [6], such as affordable shops and eating outlets, which are common locations where Hong Kong older adults socialise [49]. Additionally, neighbourhoods with high entertainment density may be excessively crowded and noisy at night, tailored to younger people and their services and facilities may be overpriced for retirees. This could contribute to older adults' feeling dissatisfied and socially isolated.

Parks and other public open spaces, where older residents can engage in physical and social activities [50], are another destination category hypothesised to benefit QoL [3,11]. However, in the fully-adjusted multiple-neighbourhood-attribute models, social QoL was negatively related to the number of parks in the neighbourhood and positively related to the prevalence of trees in parks. Additionally, the total number of activity types available in neighbourhood parks buffered the negative 
effects of living alone on social QoL. It appears that the mere presence of many small parks may be detrimental to social QoL because it reduces the amount of land available for other uses that promote utilitarian walking and social interactions (e.g., eateries, shops and community services). Our findings suggest that, to promote social interactions and activities among older residents, neighbourhoods should provide access to one or two well-treed parks offering opportunities for diverse recreational activities. Having parks with a mature tree canopy cover is important not only for aesthetics and restorative reasons [51,52]. A tree's canopy acts like a parasol. It cools the surrounding environment and provides shady areas where people can meet, which are important considerations in an ultra-dense, built-up, subtropical urban environment such as Hong Kong.

It is interesting that older adults having access to a wide range of activities in local parks had higher social QoL if living alone than living with others. Parks providing different activities are likely to be more frequently visited by a larger number of residents, which increases the opportunity for older adults living alone to develop and maintain social relations with likeminded neighbours. In contrast, those living with others may commit themselves to spending more time with household members within their typically overcrowded apartment, which would result in heightened levels of stress and, thus, negative social perceptions $[53,54]$.

Another interesting moderating effect of park accessibility on the associations between living arrangements and QoL was found in relation physical QoL. Compared to those living with others, older people living alone reported lower physical QoL when residing in neighbourhoods intersected by larger park areas. In Hong Kong, these types of neighbourhoods are located in areas adjacent to country parks or natural reserves, which are often typified by steep terrain [55] and have restricted access to public transport and daily destinations. Older adults living in such neighbourhoods have limited opportunities to engage in active travel [4] and other forms of physical activity [56], which may compromise their health and result in lower levels of physical QoL. This would be especially the case for those living alone who, in absence of support from others, need to negotiate the challenging environmental conditions they live in and may develop less favourable perceptions of their physical capacity. Yet, given that this was the only significant environmental moderating effect found with respect to physical QoL, it might have been due to chance.

Signs of crime/disorder moderated the associations between living arrangements and psychological QoL. Compared to those living with others, older people living alone reported higher psychological QoL when residing in neighbourhoods with more signs of crime/disorder. However, it should be noted that the levels of signs of crime/disorder in our study were very low (on average 0.3 out of 100 points), which is typical of Hong Kong residential neighbourhoods [57]. Some signs of crime/disorder can be observed in destination-rich, lower SES neighbourhoods [58]. Older adults living alone in these low SES areas may spend more time outside their small apartments than those living with others and capitalise on the affordable opportunities for activities offered by their communities [26], which would benefit their psychological well-being.

Two non-destination aspects of the environment that emerged as correlates of QoL domains in the whole sample were the presence of litter and/or decay and street intersection density. Whilst the former characteristic was, as anticipated, negatively associated with environmental QoL, the latter showed somewhat unexpected negative associations with environmental and social QoL. In Hong Kong, areas with a lot of street intersections (i.e., a dense street network) are also ultra-dense, filled with high-rise buildings, heavily trafficked and, hence, polluted and noisy [59], which may explain why this attribute was negatively related to older adults' environmental QoL.

Finally, the small number of significant associations between the examined neighbourhood characteristics and QoL in the whole sample of older adults requires an explanation. Studies on factors influencing Hong Kong older adults' physical activity, a lifestyle behaviour beneficial to QoL, identified a substantial number of neighbourhood physical attributes associated with walking within the neighbourhood $[49,60]$ but very few attributes related to total walking [49]. Yet, it is total rather than location-specific physical activity that benefits health [61]. It has been suggested that most Hong 
Kong older residents living in neighbourhoods with poorer access to destinations can engage in health-enhancing levels of physical activity (and other QoL-enhancing activities) due to Hong Kong's ubiquitous, efficient, affordable and highly integrated public transport network which allows them to get to neighbourhoods with destinations that meet their needs $[49,62]$. Therefore, it is possible that Hong Kong's public transport system in conjunction with a relatively low percentage of older adults living alone might have been responsible for the overall lack of main effects observed in this study. The fact that this sample had higher average scores on the environmental and social QoL scales than those observed in other geographical locations [63] further supports for this idea, although it should be acknowledged that because the sampling strategy used in this study was not meant to provide a representative sample of the whole Hong Kong population of older adults, these QoL estimates may be biased. Pooled analyses of multi-country data with a greater variability in environmental exposures are needed to more accurately quantify dose-response relationships between neighbourhood physical attributes and QoL.

There are several strengths and limitations to our study. We assessed a large range of neighbourhood physical environmental attributes using objective methods that allowed us to control for a major potential source of reserve causality common in this research field-namely, positive affective states and better health status (high QoL) causing older adults to perceive their environment more favourably. This being a cross-sectional observational study, we cannot rule out an effect of neighbourhood self-selection bias on the findings. However, concerns about neighbourhood self-selection are mitigated by the study sampling design ensuring a balanced representation of high and low walkable neighbourhoods across SES strata [64]. Additionally, this particular threat to internal validity is alleviated by the fact that $37 \%$ of Hong Kong elderly live in public rental housing [54] and most of them have limited choice of accommodation due to Hong Kong's sky-high residential property prices. Another study limitation pertains to the inability to employ a more comprehensive sampling frame for participant recruitment due to privacy ordinance restrictions. However, the relatively high response rate in this study alleviates concerns related to sampling bias. A further limitation is the lack of detailed information on household composition (e.g., being able to distinguish between living with a partner versus living with children or extended family) which would have helped clarify how the neighbourhood environment interacts with living conditions to affect older adults' QoL. Further, the neighbourhood environment is likely to have stronger effects on the QoL of older adults who live alone and suffer from chronic health problems [60] than those who live alone and are relatively healthy. Therefore, it would be useful for future studies to examine the interplay of the neighbourhood environment, living arrangements and health status on older adults' QoL. Finally, due to logistic limitations, this study used different types of residential buffers (crow-fly and street-network) to define 'neighbourhoods' and examined differences in associations between buffer sizes for only a small number of environmental attributes. Hence, the issue of optimal buffer size for studying environmental correlates of QoL in older adults remains unresolved. Future research in this field needs to address these limitations and aim for well-designed longitudinal and quasi-experimental studies providing more robust estimates of causal effects.

\section{Conclusions}

Medium-to-high density, well-ordered neighbourhoods with an optimal mix of well-treed public open spaces and services catering for older adults' daily needs may significantly contribute to the social and environmental QoL of an ageing population in Hong Kong. Easy access to a variety of daily destinations and activities in local parks appears to be particularly important to the social and environmental QoL of older people living alone who are self-reliant in performing activities of daily living. The extent to which these findings are generalisable to other Asian mega-cities needs to be examined in future studies.

Supplementary Materials: The following are available online at http:/ /www.mdpi.com/1660-4601/16/5/876/s1, Figure S1: Curvilinear associations of single neighbourhood attributes with quality of life (QoL), Table S1: 
Definitions of environmental variables and expected associations with quality of life (QoL), Table S2: Associations of socio-demographic and health-related characteristics with quality of life (QoL) domains, Table S3: Associations between single GIS neighbourhood environmental attributes based on $400 \mathrm{~m}$ street-network buffers and quality of life (QoL) domains.

Author Contributions: Conceptualization, A.B. and E.C.; Data curation, C.J.P.Z.; Formal analysis, C.J.P.Z. and E.C.; Funding acquisition, E.C.; Methodology, C.J.P.Z. and E.C.; Project administration, C.J.P.Z., R.S.Y.L. and E.C.; Resources, J.M.J., P.-c.L., R.S.Y.L. and C.H.P.S.; Supervision, C.J.P.Z., A.B., J.M.J., P.-c.L. and E.C.; Visualization, E.C.; Writing—original draft, C.J.P.Z.; Writing—review \& editing, A.B., J.M.J., P.-c.L., R.S.Y.L., C.H.P.S. and E.C.

Funding: This study received a General Research Fund grant from the University Grant Committee, Hong Kong (HKU 741511H). Ester Cerin is supported by an Australian Research Council Future Fellowship (FT14010085). The funding bodies had no role in the design of the study, interpretation of the data, decision to publish, or writing of the manuscript.

Conflicts of Interest: The authors declare no conflicts of interest.

\section{References}

1. World Health Organisation. WHOQOL: Measuring Quality of Life. 1997. Available online: http://www. who.int/mental_health/media/68.pdf (accessed on 27 April 2018).

2. Megari, K. Quality of life in chronic disease patients. Health Psychol. Res. 2013, 1, e27. [CrossRef] [PubMed]

3. Parra, D.C.; Gomez, L.F.; Sarmiento, O.L.; Buchner, D.; Brownson, R.; Schimd, T.; Gomez, V.; Lobelo, F. Perceived and objective neighborhood environment attributes and health related quality of life among the elderly in Bogotá, Colombia. Soc. Sci. Med. 2010, 70, 1070-1076. [CrossRef] [PubMed]

4. Cerin, E.; Nathan, A.; van Cauwenberg, J.; Barnett, D.W.; Barnett, A. The neighbourhood physical environment and active travel in older adults: A systematic review and meta-analysis. Int. J. Behav. Nutr. Phys. 2017, 14, 15. [CrossRef] [PubMed]

5. Barnett, A.; Zhang, C.J.P.; Johnston, J.M.; Cerin, E. Relationships between the neighbourhood environment and depression in older adults: A systematic review and meta-analysis. Int. Psychogeriatr. 2018, 30, 1153-1176. [CrossRef] [PubMed]

6. Jones, M.; Pebley, A.R. Redefining neighborhoods using common destinations: Social characteristics of activity spaces and home census tracts compared. Demography 2014, 51, 727-752. [CrossRef] [PubMed]

7. Leslie, E.; Cerin, E. Are perceptions of the local environment related to neighbourhood satisfaction and mental health in adults? Prev. Med. 2008, 47, 273-278. [CrossRef] [PubMed]

8. Oiamo, T.H.; Luginaah, I.N.; Baxter, J. Cumulative effects of noise and odour annoyances on environmental and health related quality of life. Soc. Sci. Med. 2015, 146, 191-203. [CrossRef] [PubMed]

9. Byles, J.E.; Mackenzie, L.; Redman, S.; Parkinson, L.; Leigh, L.; Curryer, C. Supporting housing and neighbourhoods for healthy ageing: Findings from the Housing and Independent Living Study (HAIL). Australas J. Ageing 2014, 33, 29-35. [CrossRef] [PubMed]

10. Friedman, D.; Parikh, N.S.; Giunta, N.; Fahs, M.C.; Gallo, W.T. The influence of neighborhood factors on the quality of life of older adults attending New York City senior centers: Results from the Health Indicators Project. Qual. Life Res. 2012, 21, 123-131. [CrossRef] [PubMed]

11. Sugiyama, T.; Thompson, C.W.; Alves, S. Associations between neighborhood open space attributes and quality of life for older people in Britain. Environ. Behav. 2009, 41, 3-21. [CrossRef]

12. Van den Berg, M.; Van Poppel, M.; Van Kamp, I.; Andrusaityte, S.; Balseviciene, B.; Cirach, M.; Danileviciute, A.; Ellis, N.; Hurst, G.; Masterson, D.; et al. Visiting green space is associated with mental health and vitality: A cross-sectional study in four european cities. Health Place 2016, 38, 8-15. [CrossRef] [PubMed]

13. Chapman, N.J.; Beaudet, M. Environmental predictors of well-being for at-risk older adults in a mid-sized city. J. Gerontol. 1983, 38, 237-244. [CrossRef] [PubMed]

14. Engel, L.; Chudyk, A.M.; Ashe, M.C.; McKay, H.A.; Whitehurst, D.G.T.; Bryan, S. Older adults' quality of life-Exploring the role of the built environment and social cohesion in community-dwelling seniors on low income. Soc. Sci. Med. 2016, 16, 1-11. [CrossRef] [PubMed]

15. Lucumí, D.I.; Gomez, L.F.; Brownson, R.C.; Parra, D.C. Social capital, socioeconomic status, and health-related quality of life among older adults in Bogotá (Colombia). J. Aging Health 2015, 27, 730-750. [CrossRef] [PubMed] 
16. Smith, A.E.; Sim, J.; Scharf, T.; Phillipson, C. Determinants of quality of life amongst older people in deprived neighbourhoods. Ageing Soc. 2004, 24, 793-814. [CrossRef]

17. Vogt, S.; Mielck, A.; Berger, U.; Grill, E.; Peters, A.; Doring, A.; Holle, R.; Strobl, R.; Zimmermann, A.K.; Linkohr, B.; et al. Neighborhood and healthy aging in a German city: Distances to green space and senior service centers and their associations with physical constitution, disability, and health-related quality of life. Eur. J. Ageing 2015, 12, 273-283. [CrossRef] [PubMed]

18. Kuppens, P.; Realo, A.; Diener, E. The role of positive and negative emotions in life satisfaction judgment across nations. J. Personal. Soc. Psychol. 2008, 95, 66-75. [CrossRef] [PubMed]

19. Vanlessen, N.; De Raedt, R.; Koster, E.H.W.; Pourtois, G. Happy heart, smiling eyes: A systematic review of positive mood effects on broadening of visuospatial attention. Neurosci. Biobehav. Rev. 2016, 68, 816-837. [CrossRef] [PubMed]

20. Zhang, C.J.P.; Barnett, A.; Sit, C.H.P.; Lai, P.C.; Johnston, J.M.; Cerin, E. Cross-sectional associations of objectively-assessed neighbourhood attributes with depressive symptoms in older adults of an ultra-dense urban environment. BMJ Open 2018, 8, e020480. [CrossRef] [PubMed]

21. Balfour, J.L.; Kaplan, G.A. Neighborhood environment and loss of physical function in older adults: Evidence from the Alameda County Study. Am. J. Epidemiol. 2002, 155, 507-515. [CrossRef] [PubMed]

22. Zadra, J.R.; Clore, G.L. Emotion and perception: The role of affective information. Wiley Interdiscip. Rev. Cogn. Sci. 2011, 2, 676-685. [CrossRef] [PubMed]

23. Cerin, E.; Zhang, C.J.P.; Barnett, A.; Sit, C.H.P.; Cheung, M.M.; Johnston, J.M.; Lai, P.C.; Lee, R.S. Associations of objectively-assessed neighborhood characteristics with older adults' total physical activity and sedentary time in an ultra-dense urban environment: Findings from the ALECS study. Health Place 2016, 42, 1-10. [CrossRef] [PubMed]

24. Cerin, E.; Chan, K.W.; Macfarlane, D.J.; Lee, K.Y.; Lai, P.C. Objective assessment of walking environments in ultra-dense cities: Development and reliability of the Environment in Asia Scan Tool-Hong Kong version (EAST-HK). Health Place 2011, 17, 937-945. [CrossRef] [PubMed]

25. McLaren, L.; Hawe, P. Ecological perspectives in health research. J. Epidemiol. Community Health 2005, 59, 6-14. [CrossRef] [PubMed]

26. Hays, J.C. Living arrangements and health status in later life: A review of recent literature. Public Health Nurs. 2002, 19, 136-151. [CrossRef] [PubMed]

27. Chou, K.L.; Chi, I. Stressful events and depressive symptoms among old women and men: A longitudinal study. Int. J. Aging Hum. Dev. 2000, 51, 275-293. [CrossRef] [PubMed]

28. Bongaarts, J.; Zimmer, Z. Living arrangements of older adults in the developing world: An analysis of demographic and health survey household surveys. J. Gerontol. B Psychol. Sci. Soc. Sci. 2002, 57, S145-S157. [CrossRef] [PubMed]

29. Census and Statistics Department. Hong Kong SAR. The Profile of the Population in One-Person Households in 2011. 2013. Available online: https://www.statistics.gov.hk/pub/B71303FA2013XXXXB0100.pdf (accessed on 11 June 2018).

30. Zhu, X.; Yu, C.Y.; Lee, C.; Lu, Z.; Mann, G. A retrospective study on changes in residents' physical activities, social interactions, and neighborhood cohesion after moving to a walkable community. Prev. Med. 2014, 69, S93-S97. [CrossRef] [PubMed]

31. Cerin, E.; Sit, C.H.; Zhang, C.J.; Barnett, A.; Cheung, M.M.; Lai, P.C.; Johnston, J.M.; Lee, R.S. Neighbourhood environment, physical activity, quality of life and depressive symptoms in Hong Kong older adults: A protocol for an observational study. BMJ Open 2016, 6, e010384. [CrossRef] [PubMed]

32. Schooling, C.M.; Lam, T.H.; Li, Z.B.; Ho, S.Y.; Chan, W.M.; Ho, K.S.; Tham, M.K.; Cowling, B.J.; Leung, G.M. Obesity, physical activity, and mortality in a prospective Chinese elderly cohort. Arch. Intern. Med. 2006, 166, 1498-1504. [CrossRef] [PubMed]

33. Privacy Commissioner for Personal Data, Hong Kong. 2013. Personal Data (Privacy) Ordinance. Available online: https: / www.pcpd.org.hk/english/files/pdpo.pdf (accessed on 20 April 2018).

34. Adams, M.; Frank, L.D.; Schipperijn, J.; Smith, G.; Chapman, J.; Christiansen, L.B.; Coffee, N.; Salvo, D.; du Toit, L.; Dygrýn, J.; et al. International variation in neighborhood walkability, transit, and recreation environments using geographic information systems: The IPEN adult study. Int. J. Health Geogr. 2014, 13, 43. [CrossRef] [PubMed] 
35. Oliver, L.N.; Schuurman, N.; Hall, A.W. Comparing circular and network buffers to examine the influence of land use on walking for leisure and errands. Int. J. Health Geogr. 2007, 6, 41. [CrossRef] [PubMed]

36. Broomhall, M.H.; Giles-Corti, B.; Lange, A. Quality of Public Open Space Tool (POST); School of Population Health, The University of Western Australia: Perth, Australia, 2004.

37. Leung, K.F.; Tay, M.; Cheng, S.; Lin, F. Hong Kong Chinese Version World Health Organisation Quality of Life-Abbreviated Version; Hong Kong Hospital Authority: Hong Kong, China, 1997.

38. The WHOQOL group. Development of the World Health Organization WHOQOL-BREF quality of life assessment. The WHOQOL Group. Psychol. Med. 1998, 28, 551-558. [CrossRef]

39. Wood, S.N. Generalised Additive Models: An Introduction with R, 2nd ed.; Chapman \& Hall/CRC: Boca Raton, FL, USA, 2006.

40. Bland, J.M.; Altman, D.G. Multiple significance tests: The Bonferroni method. BMJ 1995, 310, 170. [CrossRef] [PubMed]

41. Michels, K.B.; Rosner, B.A. Data trawling: To fish or not to fish. Lancet 1996, 348, 1152-1153. [CrossRef]

42. Warnes, G.R.; Bolker, B.; Lumley, T.; Johnson, R.C. gmodels: Various R Programming Tools for Model Fitting. 2015. Available online: https://cran.r-project.org/web/packages/gmodels/gmodels.pdf (accessed on 27 April 2018).

43. Wood, S.N.; Pya, N.; Säfken, B. Smoothing parameter and model selection for general smooth models. J. Am. Stat. Assoc. 2016, 111, 1548-1563. [CrossRef]

44. Jones-Rounds, M.L.; Evans, G.W.; Braubach, M. The interactive effects of housing and neighbourhood quality on psychological well-being. J. Epidemiol. Community Health 2014, 68, 171-175. [CrossRef] [PubMed]

45. Gobbens, R.J.J.; van Assen, M. Associations of Environmental Factors with Quality of Life in Older Adults. Gerontologist 2018, 58, 101-110. [CrossRef] [PubMed]

46. Sallis, J.F.; Cerin, E.; Conway, T.L.; Adams, M.A.; Frank, L.D.; Pratt, M.; Salvo, D.; Schipperijn, J.; Smith, G.; Cain, K.L.; et al. Physical activity in relation to urban environments in 14 cities worldwide: A cross-sectional study. Lancet 2016, 387, 2207-2217. [CrossRef]

47. Fleming, I.; Baum, A.; Weiss, L. Social density and perceived control as mediators of crowding stress in high-density residential neighborhoods. J. Personal. Soc. Psychol. 1987, 52, 899-906. [CrossRef]

48. Almeida, D.M.; Piazza, J.R.; Stawski, R.S.; Klein, L.C. The speedometer of life: Stress, health and aging. In Handbook of the Psychology of Aging, 7th ed.; Schaie, K.W., Willis, S.L., Eds.; Academic Press: San Diego, CA, USA, 2011; pp. 191-206.

49. Cerin, E.; Lee, K.Y.; Barnett, A.; Sit, C.H.P.; Cheung, M.C.; Chan, W.M.; Johnston, J.M. Walking for transportation in Hong Kong Chinese urban elders: A cross-sectional study on what destinations matter and when. Int. J. Behav. Nutr. Phys. Act. 2013, 10, 78. [CrossRef] [PubMed]

50. Schipperijn, J.; Cerin, E.; Adams, M.A.; Reis, R.; Smith, G.; Cain, K.; Christiansen, L.B.; van Dyck, D.; Gidlow, C.; Frank, L.D.; et al. Access to parks and physical activity: An eight country comparison. Urban For. Urban Green. 2017, 27, 253-263. [CrossRef] [PubMed]

51. Ekkel, E.D.; de Vries, S. Nearby green space and human health: Evaluating accessibility metrics. Landsc. Urban Plan. 2017, 157, 214-220. [CrossRef]

52. Takano, T.; Nakamura, K.; Watanabe, M. Urban residential environments and senior citizens' longevity in megacity areas: The importance of walkable green spaces. J. Epidemiol. Community Health 2002, 56, 913-918. [CrossRef] [PubMed]

53. Evans, G.W.; Wells, N.M.; Moch, A. Housing and mental health: A review of the evidence and a methodological and conceptual critique. J. Soc. Issues 2003, 59, 475-500. [CrossRef]

54. Transport and Housing Bureau. Government of the Hong Kong Special Administrative Region. Hong Kong: The Facts (Housing). 2016. Available online: https://www.thb.gov.hk/eng/psp/publications/housing/ hongkongthefacts/index.htm (accessed on 11 June 2018).

55. Agriculture Fisheries and Conservation Department, Government of the Hong Kong Special Administrative Region. Hong Kong: The Facts (Country Parks and Conservation). Available online: http:/ / www.afcd.gov. hk/english/country/cou_lea/the_facts.html (accessed on 27 April 2018).

56. Barnett, D.W.; Barnett, A.; Nathan, A.; Van Cauwenberg, J.; Cerin, E. Built environmental correlates of older adults' total physical activity and walking: A systematic review and meta-analysis. Int. J. Behav. Nutr. Phys. Act. 2017, 14, 103. [CrossRef] [PubMed] 
57. Cerin, E.; Lee, K.Y.; Barnett, A.; Sit, C.H.P.; Cheung, M.C.; Chan, W.M. Objectively-measured neighborhood environments and leisure-time physical activity in Chinese urban elders. Prev. Med. 2013, 56, 86-89. [CrossRef] [PubMed]

58. Cerin, E.; Mellecker, R.; Macfarlane, D.J.; Barnett, A.; Cheung, M.C.; Sit, C.H.; Chan, W.M. Socioeconomic status, neighborhood characteristics, and walking within the neighborhood among older Hong Kong Chinese. J. Aging Health 2013, 25, 1425-1444. [CrossRef] [PubMed]

59. Zhong, J.; Cai, X.M.; Bloss, W.J. Coupling dynamics and chemistry in the air pollution modelling of street canyons: A review. Environ. Pollut. 2016, 214, 690-704. [CrossRef] [PubMed]

60. Barnett, A.; Cerin, E.; Zhang, C.J.P.; Sit, C.H.P.; Johnston, J.M.; Cheung, M.M.C.; Lee, R.S.Y. Associations between the neighbourhood environment characteristics and physical activity in older adults with specific types of chronic conditions: The ALECS cross-sectional study. Int. J. Behav. Nutr. Phys. Act. 2016, 13, 53. [CrossRef] [PubMed]

61. Gouveia, E.R.Q.; Gouveia, B.R.; Ihle, A.; Kliegel, M.; Maia, J.A.; I Badia, S.B.; Freitas, D.L. Correlates of health-related quality of life in young-old and old-old community-dwelling older adults. Qual. Life Res. 2017, 26, 1561-1569. [CrossRef] [PubMed]

62. Cerin, E.; Sit, C.H.; Barnett, A.; Johnston, J.M.; Cheung, M.C.; Chan, W.M. Ageing in an ultra-dense metropolis: Perceived neighbourhood characteristics and utilitarian walking in Hong Kong elders. Public Health Nutr. 2014, 17, 225-232. [CrossRef] [PubMed]

63. Skevington, S.M.; Lotfy, M.; O'Connell, K.A. The World Health Organization's WHOQOL-BREF quality of life assessment: Psychometric properties and results of the international field trial. A report from the WHOQOL group. Qual Life Res. 2004, 13, 299-310. [CrossRef] [PubMed]

64. Cerin, E.; Sit, C.H.P.; Cheung, M.C.; Ho, S.Y.; Lee, L.C.; Chan, W.M. Reliable and valid NEWS for Chinese seniors: Measuring perceived neighborhood attributes related to walking. Int. J. Behav. Nutr. Phys. Act. 2010, 7, 84. [CrossRef] [PubMed]

(C) 2019 by the authors. Licensee MDPI, Basel, Switzerland. This article is an open access article distributed under the terms and conditions of the Creative Commons Attribution (CC BY) license (http:// creativecommons.org/licenses/by/4.0/). 